\title{
Measurements of Swimming Speeds of Yellowfin Tuna and Wahoo
}

Bainbridge and Nursall' have questioned the validity of certain fish swimming speed estimates because these require that either completely laminar flow or very high power factors must be postulated in order to explein the animals' performance. Speeds in excess of $45 \mathrm{~km} / \mathrm{h}$ are included in this suspect category. Walters showed that certain morphological features indicate that scombroid fishes may attain velocities of 10 body-lengths/sec, and the large species should be able to attain maximum speeds considerably in excess of $45 \mathrm{~km} / \mathrm{h}$.

An opportunity of measuring scombroid swimming speods arose when the junior author was invited to participate in a tuna behaviour research oruise off the Proifio coast of Costa Rica. The measuring equipment consisted of a spinning rod and a spinning reol containing fishing line marked with iron powder. A magnetic pick-up was mounted near the tip of the rod, so that when a hooked fish pulled line from the reel, the magnetic field was disturbed by the iron powder markings. The resulting electrical signal was fed into a tape-recorder.

The magnetic pick-up consisted of a monaural variable reluotance phonograph cartridge (General Electric Model $4 Q-050)$ modified by removal of the stylus assembly and mounted in a $1.6 \mathrm{~cm} \times 1.6 \mathrm{~cm} \times 1.6 \mathrm{~cm}$ aluminium box (Fig. 1). The line passage was a $1.6 \mathrm{~cm}$ length of $2 \mathrm{~mm}$ inside diam. plastic tube into which the magnetic poles projected. The entire box, except for the line passage, was then filled with epoxy resin. The recording unit was mounted on the rod, midway between the two distal line guides. The output leads were connected to a portable tepe-recorder (Transmagnemite model 612SDV(8106)).

Braided linen fishing line of 18- and 27-lb. test was marked at $2.54 \mathrm{~cm}$ intervals with powdered iron susponded in collodion and methyl ethyl ketone. A feather ot bone

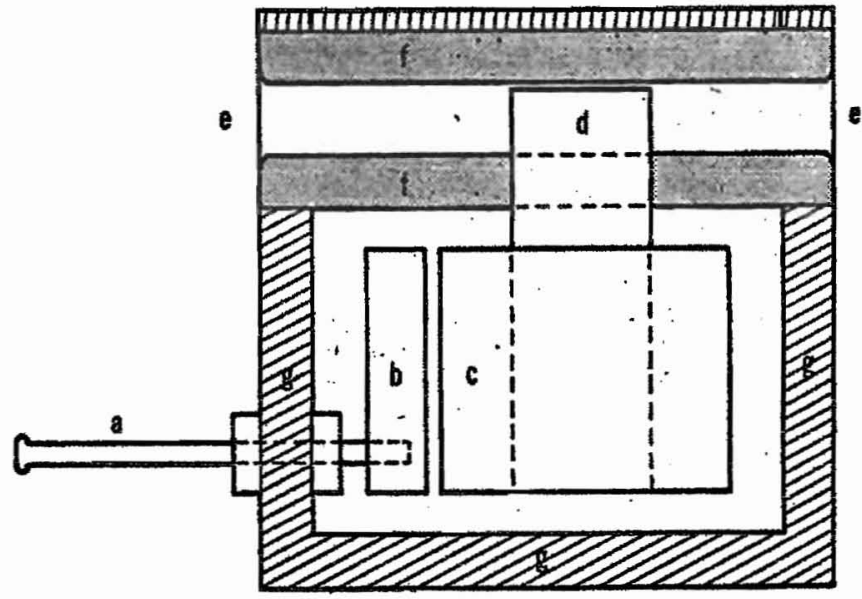

Tig. 1. Iongitudinal section through the magnetio plok-np unith $a$, Output terminal ; $b$, magnet; $c$, coll $d$, magnet pole ; $e$, line pasage; f. plastdo thbe ; go sluminium box 

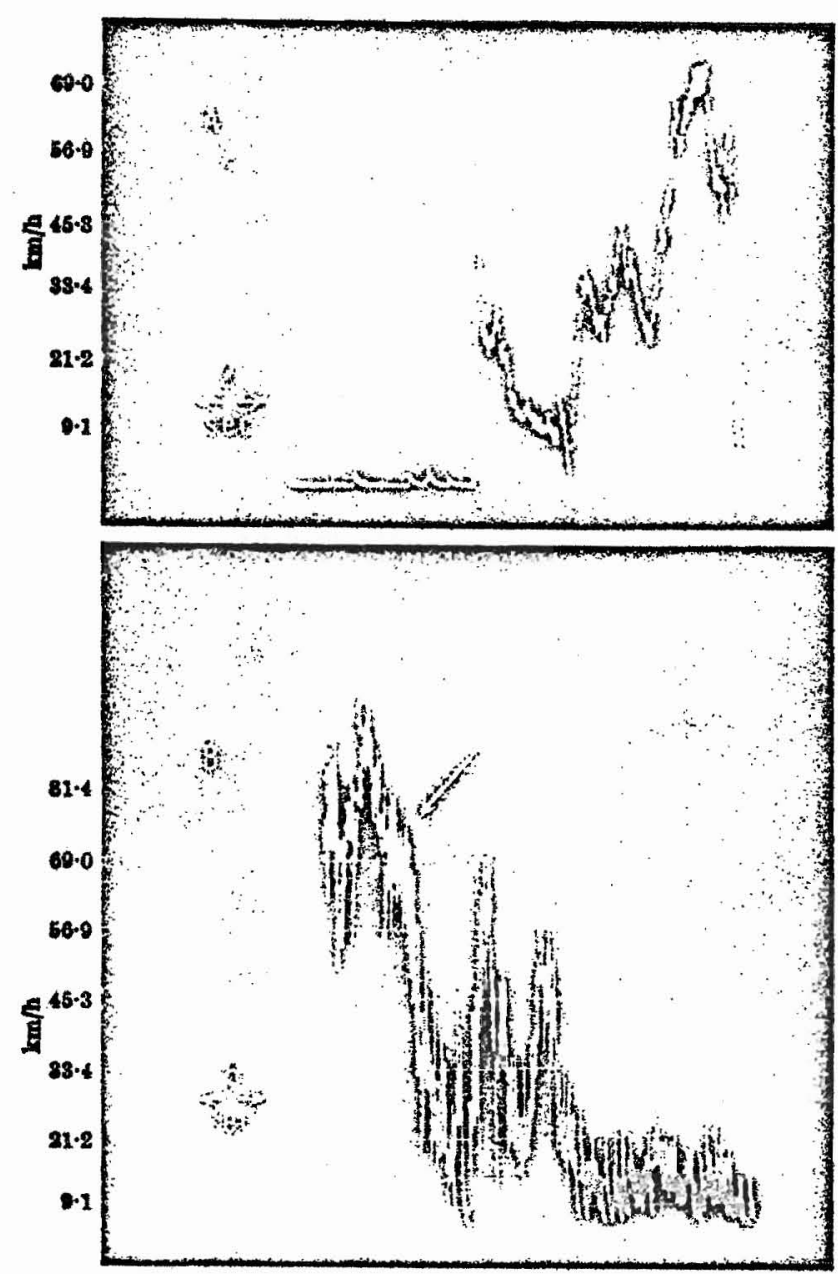

Fig. 2. Tixample of two oscillograms of swimming speeds A, Wahoo $D$; the recording ended obruptiy when the Iron powder markings were whipped of the flshing line before entering the magnetic plck-up unit. $B$, yellowin $D$; the arrow indicates the maximum speed chosen after the 5 - 260 dels

jig attached to a 2-m wire leader was connected to the marked line and trolled behind a skiff. When a fish was hooked, the skiff operator shut off the outboard motor and furned the skiff $90^{\circ}$. The rod was pointed at the fish to minimize the action of the pole. Once the line had paseed through the pick-up, it could not be rewound on the reel because the wet markings would scrape off inside the cartridge. It was thus necessary to handline each fish to the skiff, and often a fish either escaped or was attacked by a shark before it could be boated.

Swimming speed measurements of yellowin tuna, Thunnus albacares (Bonnaterre), were only taken in pure yellowfin aohools, 80 the fish were identifiable even though they may not have been seen. The mother vessel was

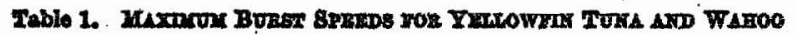

\begin{tabular}{|c|c|c|}
\hline Epecimen & $\begin{array}{l}\text { Total length } \\
\text { (mm) }\end{array}$ & $\begin{array}{l}\text { Burst Body-lengthas } \\
\text { velocith } \\
\text { (km/h) meh seo }\end{array}$ \\
\hline Yollowen 4 & $558-870$ & $35.8722 .311 \cdot 47$ \\
\hline Xollowin $B$ & $558-870$ & $24.88^{-} 15 ., 5 \quad 7.95$ \\
\hline Tellowtin $\sigma$ & $558-870$ & $\begin{array}{llll}18.83 & 11.7 & 0.01\end{array}$ \\
\hline Tellowin D & $530-980$ & $74.59 \quad 46.421 .71$ \\
\hline Xellowin $B$ & $630-980$ & $45.25-12.81$ \\
\hline Wahoo 4 & 1,000 & $43.7127 .2 \times 12.15$ \\
\hline Waboo $O$ & 920 & $48.8527 .0 \quad 13.09$ \\
\hline Wahoo D & 1,181 & 77.05 it \\
\hline
\end{tabular}

trolling at the same time with similar lures and caught onily yellowfin tuna; the size ranges are give: fish that were brought aboard the larger vessel (i i inle 1). The larger body sizes were used to caloulate the bodylengths/sec.

The identification and capture of wahoo, Acanthocybium solandri (Cuvier), was easior. On striking the lure, the wahoo always jumped clear of the water and could be identified at that time. They were brought aboard, the skiff for measurement.

The recordings were analysed in the laboratory. The tape-reoorder output was fed through a rectifier to filter out the background noise and then into a converter (Foxboro model $F R-73-4$ ) that transformed the variable frequency into a variable d.c. voltage. This voltage was then fed into an oscilloscope that had previously been calibrated with known frequencies. The oscillograph. tracings were recorded photographically. Since it took an estimated 5 sec to bring the skiff to a stop, the first 5 sec of each tape-recording were not used for swimming speed measurements.

The highest peaks taken from the oseillograph tracings (Fig. 2) after the initial 5 sec are aummarized in Table 1. These burgt velocities were present only in the first 10-20 sec after the fish was hooked, after which the velocities dropped to much lower values. The drop in line velocity could have resulted if the fish had changed course; in some cases the line went entirely slack, indicating the fish had indeed reversed its direction.

Other faetore that may have reduced the line velocities are the drag of the fishing line, the drag of the lure, and the probable turbulence induced in the boundary layer of the fish by the line and lure. No measurements were made of these values. It is felt that yellowfin tuna and wahoo can probably attain higher velocities than are reported here.

We thank the personnel of the U.S. Fiah and Wildlife Service, Bureau of Commercial Fisheries Biological Laboratory, San Diego, California, who helped one of us (H. L. F.) while aboard their charter vessel M.V. Red Rooster during Maroh-Juno, 1963 ; and Mr. Aaron Klain; of tho Department of Zoology, who designed and built com. ponents and gave advice concerning the electronic instru. mentation. This work was supported by contract $N R 104$ 669 between the University of California and the Biology Branch of the Office of Naval Research, and by a V.S. Publio Frealth Service zoology heart traineeship 5166.

VIADToch WALTHES

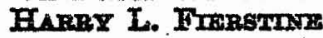

Department of Zoology,
University of Californie, Los Angeles.

- Bajnbridge, R., Probiems of Fish Incomocion, Zool. Soc. Londion, Symp., 5 , 18 (1961).

- Nursall, J. B., Amer. Zool., 2, 127 (1962).

- Walteri, V., Amer. Zool., 8, 143 (1962). 